\title{
REVIEW
}

\section{Pulmonary arteriovenous malformation}

\section{Khurshid, G H Downie}

Postgrad Med J 2002;78:191-197

Pulmonary arteriovenous malformations (PAVM) are rare pulmonary vascular anomalies. Although most patients are asymptomatic, PAVMs can cause dyspnoea from right-to-left shunt. Because of paradoxical emboli, various central nervous system complications have been described including stroke and brain abscess. There is a strong association between PAVM and hereditary haemorrhagic telangiectasia. Chest radiography and contrast enhanced computed tomography are essential initial diagnostic tools but pulmonary angiography is the gold standard. Contrast echocardiography is useful for diagnosis and monitoring after treatment. Most patients should be treated. Therapeutic options include angiographic embolisation with metal coil or balloon occlusion and surgical excision.

See end of article for authors' affiliations

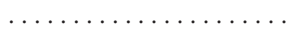

Correspondence and reprint requests to:

Dr Imtiaz Khurshid,

Department of Pulmonary and Critical Care

Medicine, Brody School of Medicine, East Carolina University, Greenville, NC

27834, USA;

khurshidi@mail.ecu.edu

Submitted 22 June 2001

Accepted

22 October 2001
D irect communications between the branches of pulmonary artery and pulmonary veins, without an intervening pulmonary bed, are probably the most common anomalies of the pulmonary vascular tree and have been variously called a pulmonary arteriovenous fistula, pulmonary arteriovenous malformation (PAVM), pulmonary arteriovenous aneurysm (PAVA), pulmonary angioma, arteriovenous angiomatosis, cavernous haemangiomas, and pulmonary hamartomas. ${ }^{12}$ The lesions usually represent congenital malformation, with the exception of very rare acquired cases, and lack malignant potential; hence the later four terms do not properly represent this entity. Additionally the term PAVA preferentially represents lesions associated with circumscribed dilatation of the pulmonary artery or vein which are visible at angiography or gross inspection. The terms pulmonary arteriovenous fistula and PAVM with arteriovenous shunt can be used interchangeably. PAVM is the preferred term, since it represents a developmental defect.

\section{HISTORICAL BACKGROUND}

The first description of PAVM was reported by Churton in $1897 .{ }^{3}$ He reported the case of a 12 year old boy who had episodes of epistaxis, haemoptysis, and loud pulmonary systolic bruit; at postmortem examination he was found to have multiple bilateral PAVM. In 1917, Wilkins described the necropsy findings in a 23 year old women with cyanosis, clubbing, telangiectasia, and bilateral axillary bruits who died from haemothorax after rupture of a PAVA into the pleural cavity. ${ }^{4}$ In 1938, Rhodes recognised the association between telangiectasias and PAVAs. ${ }^{5}$ Smith and Horton in 1939 made the first clinical diagnosis of a PAVM in a 40 year old man who had cyanosis, clubbing, bruit, and polycythaemia. ${ }^{6}$ In 1942, Hepburn and Dauphinee reported the first case of successful surgical removal of a pulmonary haemangioma with disappearance of the patient's polycythaemia and clubbing after pneumonectomy. ${ }^{7}$ An alternative to lung parenchymal resection was described by Packard and Waring in 1945, who successfully treated a 31 year old man with a PAVA by ligation of the pulmonary artery. ${ }^{8}$ Surgical techniques were further refined to lobectomy, instead of pneumonectomy, in 1950 and to local excision in 1959. ${ }^{90}$ Surgery remained the mainstay of treatment until 1978 when Taylor and coworkers reported the first case of successful percutaneous catheterisation and embolisation of a PAVM. ${ }^{11}$

\section{AETIOLOGY}

Since the first reported case in 1897, more than 500 cases have been reported in the literature. ${ }^{12-16}$ The natural history of this rare entity is not completely understood. PAVMs can be either congenital or acquired. More than $80 \%$ of PAVMs are congenital, and of these $47 \%-80 \%$ are associated with Osler-Weber-Render disease or hereditary haemorrhagic telangiectasia (HHT).${ }^{13-16}$ Conversely, it is estimated that overall, $5 \%-15 \%$ of the population with HHT have a PAVM. ${ }^{13-17}$ It is clear that stigmata of either of these two entities should alert the clinician to the possibility that both may coexist. In patients with HHT, telangiectases of the skin and oral, nasal, and conjunctival mucosa become apparent in the second and third decades of life. The presence of HHT in a patient with a PAVM may be of prognostic value since the patient with coexisting HHT tends to have worse symptomatology, multiple arteriovenous malformations, rapid disease progression, and a higher complication rate. ${ }^{13-16}$

The incidence of PAVMs apparently varies according to the specific gene alterations. ${ }^{18}{ }^{19}$ The genetic aetiological linkages to HHT are located on chromosome 9 (9q 33-34 or OWR-1) in some families and on chromosome 12 (12q or OWR-2) in others. ${ }^{18} 19$ The gene for HHT at chromosome $9 \mathrm{q} 3$ codes for endoglin, a binding membrane glycoprotein of vascular endothelial cells in arterioles, venules, and capillaries. ${ }^{18}$ The mutation of endoglin gene can cause vascular dysplasia and is

Abbreviations: 3-D, three dimensional; HHT, hereditary haemorrhagic telangiectasia; PAVA, pulmonary arteriovenous aneurysm; PAVM, pulmonary arteriovenous malformation 
seen more often in patients with genetic linkage to chromosome $9 \mathrm{q} 3 .{ }^{19}$

Secondary or acquired PAVM, although very rare, has been reported in the literature. Causes of secondary PAVM include chest trauma, thoracic surgery, long standing hepatic cirrhosis, metastatic carcinoma, mitral stenosis, infections (actinomycosis, schistosomiasis), and systemic amyloidosis. ${ }^{120-24}$ Pregnancy has been associated with an increased rate of PAVM growth and its associated complications..$^{25-28}$ An increased growth rate of a PAVM has been attributed to increased blood volume and cardiac output, which leads to increased pulmonary blood flow, preferentially across the low resistance PAVM. ${ }^{25}$ The increased blood flow across the PAVM causes its dilatation. Secondly, increased venous distensibility secondary to a progesterone effect causes further augmentation of blood flow and leads to progression in PAVM size. The pregnancy associated increase in steroid hormone synthesis results in an increased incidence of spontaneous haemothorax secondary to intrapleural rupture of PAVM. ${ }^{25} 2728$

\section{PATHOLOGY}

The incidence of PAVM is $2-3$ per 100000 population. ${ }^{17}$ The male to female ratio varies from $1: 1.5$ to 1.8 , in several series. $^{13-15}$ The age at the first presentation ranges from newborn to 70 but the majority of cases are diagnosed in the first three decades of life. ${ }^{12-14}$ PAVMs may be single or multiple in occurrence and the incidence of single PAVMs ranges from $42 \%$ to $74 \% .{ }^{10}{ }^{13} 1429$ Most solitary PAVMs are seen in bilateral lower lobes, the left lower lobe being the most common location, followed by right lower lobe, left upper lobe, right middle lobe, and right upper lobe..$^{1429}$ The majority of multiple PAVMs are also confined to bilateral lower lobes; the incidence of bilateral PAVMs ranges from $8 \%$ to $20 \%{ }^{10}{ }^{12}$

All PAVMs have an afferent supply, usually from one or more branches of the pulmonary artery. However afferent supply sometimes, in part or all, is derived from the systemic circulation; the source of systemic supply includes the aorta, intercostal and bronchial arteries. ${ }^{10}{ }^{12}$ The efferent limb of an arteriovenous malformation drains into one or more branches of the pulmonary vein; sometimes abnormal efferent vessels may drain directly into the left atrium or inferior vena cava, instead of the pulmonary vein..$^{30}$ PAVMs are usually found in close proximity to the visceral pleura or embedded in the outer third of lung parenchyma. In a study of 110 patients with a single PAVM, 89 ( $81 \%$ ) of the lesions were either subpleural or partially embedded in the lung parenchyma. ${ }^{10}$

The classification of PAVMs, including embryology and anatomic variations, has been reviewed by Anabtawi and colleagues. ${ }^{30}$ They have classified PAVMs in five groups (box 1), and this classification is based on embryological development of the lung and pulmonary vasculature. They suggest that the separate embryonic development of the pulmonary arterial, capillary, and venous systems allows anomalies of the pulmonary circulation in these systems, either in combination or as an isolated lesion. Additionally isolated abnormal development of capillaries can result in arteriovenous shunting with no visible malformation. Cooley and McNamara were the first to describe a case of microscopic PAVM, diagnosed by open lung biopsy in a cyanotic patient with normal chest radiographs and pulmonary angiogram. ${ }^{31}$ The most commonly encountered vascular anomaly is a primitive venous plexus with persistence of large vascular channels of aneurysmal proportions, which we recognise as PAVM.

\section{PATHOPHYSIOLOGY}

In contrast to systemic arteriovenous malformation, PAVMs do not affect cardiac haemodynamics. ${ }^{12} 1316$ Cardiac output, cardiac index, pulmonary capillary wedge pressure, heart rate, blood pressure, and the electrocardiogram are usually within normal limits. The fundamental defect is right-to-left shunt
Box 1: Anatomical classification of PAVMs (derived

from Anatwabi et $\mathbf{a}^{30}$ )

Group I

- Multiple small arteriovenous fistulas.

- Without aneurysm.

Group II

- Large arteriovenous aneurysm.

Group III

A. Large arteriovenous aneurysm (central).

B. Large arteriovenous aneurysm with anomalous venous drainage.

C. Multiple small arteriovenous fistulas with anomalous venous drainage.

Group IV

A. Large venous aneurysm with systemic artery communication.

B. Large venous aneurysm without fistula.

Group V

- Anomalous venous drainage with fistulas.

from the pulmonary artery to the pulmonary vein, the degree of shunt is what determines the clinical effects on the patient. ${ }^{12}{ }^{16}$ If shunting is minimal, the symptoms are usually subacute or even absent. If the right-to-left shunt is greater than $20 \%$ of the systemic cardiac output or there is reduction of haemoglobin more than $50 \mathrm{~g} / \mathrm{l}$, the patient will have obvious cyanosis, clubbing, and polycythaemia. In some cases of HHT, cyanosis may be hidden by anaemia caused by epistaxis or gastrointestinal blood. The red cell mass and blood volume are usually increased while the plasma volume is normal. ${ }^{6}{ }^{12}$ The peripheral oxygen saturation is low and as expected does not normalise with $100 \%$ oxygen.

\section{CLINICAL FINDINGS}

An accurate analysis of the clinical findings seen in PAVM is difficult because many of the published series overlap disease entities; therefore recorded data specific for PAVM are not uniform and often are incomplete. Asymptomatic patients are common and account for between $13 \%$ to $55 \%$ of patients in different series. ${ }^{13-1525}$ So absence of symptoms does not preclude the diagnosis of PAVM. The most common presenting symptom is dyspnoea on exertion, which is seen in $31 \%$ to $67 \%$ of patients (box 2). ${ }^{13-17}$ The severity of dyspnoea is related to the degree of hypoxaemia and the magnitude of the shunt. The majority of the patients with PAVMs tolerate hypoxaemia very well and are relatively or completely asymptomatic unless the arterial oxygen pressure is less than $8.0 \mathrm{kPa}(60 \mathrm{~mm} \mathrm{Hg})$. Epistaxis, melaena, and neurological symptoms should alert the clinician to the possibility of coexisting HHT. Epistaxis is relatively more common in patients with HHT. ${ }^{14}{ }^{17}$ In a sizeable number of patients $(43 \%-67 \%)$, a history of neurological symptoms-that is, headache, vertigo, paresis, numbness, paresthaesia, syncope, or confusion-can be found. ${ }^{15}{ }^{17}$ In one study, the classic triad of dyspnoea, cyanosis, and clubbing was found in only $10 \%$ of patients with a PAVM. ${ }^{32}$

A meticulous physical examination will detect abnormal physical findings in up to $75 \%$ of patients..$^{32}$ The most common physical findings are cyanosis, clubbing, and pulmonary vascular bruit (box 2). ${ }^{13}{ }^{15}$ Classically, the pulmonary bruit is increased by inspiration and the Muller manoeuvre (forced inspiration with a closed glottis after full expiration), this is caused by an increase in the pulmonary blood flow and decreased by expiration and the Valsalva manoeuvre, by decreasing venous return to the lung. Mucocutaneous telangiectasias have been reported in up to two thirds of HHT 


\section{Box 2: Clinical features of PAVMs}

Symptoms

- Dyspnoea.

- Epistaxis.

- Haemoptysis.

- Palpitation.

- Chest pain

- Cough.

Signs

- Bruit/thrill.

- Clubbing.

- Cyanosis.

- Telangiectasia

- Polycythaemia.

- Anaemia.

\section{Complications}

- Hypoxaemia

- Intrabronchial rupture, haemoptysis.

- Intrapleural rupture, haemothorax.

- Paradoxical embolisation.

- Polycythaemia.

- Pulmonary hypertension.

- Endocarditis.

- Transient ischaemic attack.

- Cerebrovascular accident.

- Migraine headache.

- Brain abscess.

- Congestive heart failure. patients with a PAVM. ${ }^{15}{ }^{17}$ Massive haemoptysis after intrabronchial rupture of a lesion or haemothorax after rupture of a subpleural lesion is rare but potentially a fatal complication of PAVM. ${ }^{25}{ }^{27}$ The presence of symptoms usually correlates with the size of lesion, a single PAVM less than $2 \mathrm{~cm}$ in diameter on chest radiography usually does not cause symptoms. ${ }^{13}{ }^{14}$

The most commonly reported complications relate to the central nervous system and the incidence varies in different series from $19 \%$ to $59 \% .^{15}{ }^{17} 2533$ In one study the reported incidence of different neurological events was as follows: migraine $43 \%$, transient ischaemic attack $37 \%$, stroke $18 \%$, abscess $9 \%$, and seizure $8 \%{ }^{33}$ The most likely mechanism for these neurological events is paradoxical embolism across the PAVM or across a coexisting cerebral arteriovenous malformation in patients with HHT. Less common but life threatening complications include haemoptysis and haemothorax. Haemoptysis may be due to intrabronchial rupture of PAVM or endobronchial telangiectasis, while haemothorax may result from rupture of a subpleural PAVM. In a study of 143 patients with PAVM, who were referred for embolotherapy, 11 (8\%) had a history of massive haemoptysis or haemothorax. ${ }^{27}$ Pulmonary haemorrhage was the presenting symptom in nine of the 11 patients, seven of the 11 patients were female, three of whom experienced symptoms during pregnancy. ${ }^{27}$

\section{DIAGNOSIS}

Chest radiography is an important diagnostic tool not only in diagnosis but also in the follow up of patients with a PAVM. A plain chest radiograph shows abnormalities in about $98 \%$ of patients. ${ }^{13-15}$ The classic radiographic features of PAVM are a round or oval sharply defined mass of uniform density, frequently lobulated, and ranging in size from $1-5 \mathrm{~cm}$ in diameter; two thirds are located in the lower lobes (figs 1 and 2). ${ }^{10}{ }^{12}{ }^{13}$ A plain chest radiograph may show a connecting vessel radiating from the hilum. ${ }^{13}{ }^{14}$ Chest tomography, although not used commonly, is more accurate in identifying connecting vessels and PAVM. ${ }^{13}$

The shunt fraction, the fraction of cardiac output that shunts from right-to-left through a PAVM, is raised in $88 \%$ to

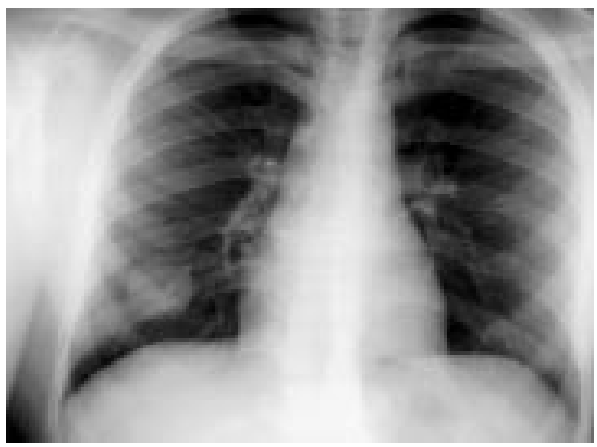

Figure 1 Posteroanterior chest radiograph showing a large, single PAVM in right lower hemithorax.

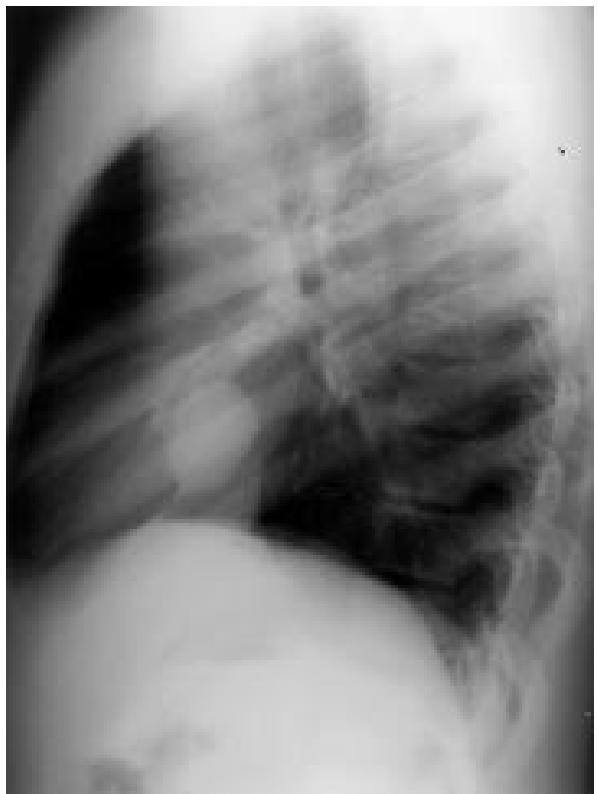

Figure 2 Lateral chest radiograph showing a large, single PAVM in right lower hemithorax.

$100 \%$ of selected patients with a PAVM..$^{13-15}{ }^{34}$ Shunt fraction is most accurately measured by the $100 \%$ oxygen method, which involves measurements of oxygen saturation and arterial oxygen pressure after breathing $100 \%$ oxygen for 15 to 20 minutes. A shunt fraction of equal to or greater than $5 \%$ by this method is considered abnormal. In a study of 32 patients, the shunt fraction ranged from $3.5 \%$ to $35 \%$ and a higher shunt fraction was observed in patients with multiple PAVM. $^{34}$

Contrast echocardiography involves injection of agitated saline or dye into a peripheral vein; it is extremely sensitive in detecting left-to-right shunt but it does not provide quantitative or anatomic detail of the shunt. In patients without rightto-left shunt, an air bubble or dye may rapidly appear in the right atrium and then gradually dissipate as the bubbles become trapped in the pulmonary circulation. ${ }^{12}$ In the case of intracardiac shunt, bubbles will be visualised in the left atrium within one cardiac cycle after their appearance in the right atrium. ${ }^{35}$ In contrast, a PAVM will demonstrate a delay of three to eight cardiac cycles before the bubbles will be visualised in the left atrium..$^{35}$ On occasion, if bubbles or contrast can be seen entering the left atrium through a single pulmonary vein, it confirms the ipsilateral anatomical localisation of the PAVM. In addition, contrast echocardiography allows assessment of efficiency of embolotherapy and is useful to exclude the presence of PAVM in family members of patients with HHT. ${ }^{36}$ 


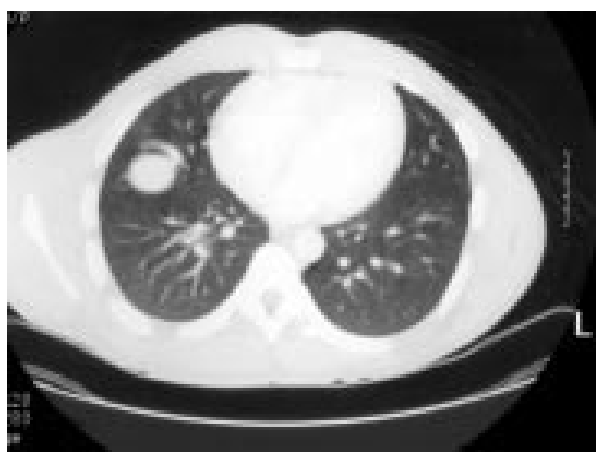

Figure 3 Computed tomogram section demonstrates a well circumscribed density in right lower lobe connected by a blood vessel.

Radionuclide perfusion lung scan is a useful adjunct in the diagnosis and quantification of PAVM.$^{36}$ However, as with contrast echocardiography, a positive result is not specific for PAVM, whereas a negative result essentially excludes the diagnosis. Radionuclide scanning also allows the quantification of shunt magnitude, the results of which are comparable to the $100 \%$ oxygen shunt calculation method. ${ }^{36}$ Like contrast echocardiography, radionuclide perfusion lung scanning does not provide information about anatomical detail of the PAVM. Despite a high negative predictive value, radionuclide perfusion lung scanning is not employed routinely.

Contrast enhanced computed tomography is a valuable tool in diagnosis and defining the vascular anatomy of PAVM (fig 3). ${ }^{37}$ Remy et al compared the usefulness of contrast enhanced computed tomography with selective pulmonary angiography and found that computed tomography scanning was significantly better than conventional angiography in detecting a PAVM (98 v 60\%). ${ }^{37}$ However, angiography was better able to determine the angioarchitecture of individual PAVMs than computed tomography. The superiority of computed tomography scanning in detecting PAVM is attributed to the absence of superimposition of lesions in transaxial computed tomography views. Three dimensional (3-D) helical computed tomography, a relatively new technique that is not widely available, is also being used for the diagnosis of pulmonary vascular lesions. In a comparative study, 3-D helical computed tomography allowed full analysis of $76 \%$ of PAVM, compared with only $32 \%$ by conventional unilateral pulmonary angiography. ${ }^{37}$ The use of 3-D helical computed tomography is limited by time, prolonged breath holding, and the inability to visualise large PAVMs. ${ }^{38}$ Additionally there have been case reports of the false positive diagnosis of PAVMs by computed tomography. ${ }^{39}$ So a contrast enhanced computed tomography scan is a useful and widely available diagnostic tool in patients with abnormal chest radiography suspicious of PAVM and also to rule out any coexisting process.

The use of magnetic resonance imaging to diagnose PAVM has been limited compared with that of computed tomography. ${ }^{40}$ Most lesions within the lung have a relatively long relaxation time and produce medium to high intensity signals. In contrast, PAVMs and aneurysms with rapid blood flow in the lesion result in a signal void and produce low intensity signals. ${ }^{42}$ Additional low signal intensity lesions include air cyst, calcified lesion, fibrous scar, cystic lesion, and haematoma. These lesions make it hard to differentiate PAVMs from these lesions with the standard magnetic resonance imaging technique, so application of additional techniques have been suggested to visualise pulmonary vascular lesions. ${ }^{40}$ There are isolated case reports of successful diagnosis of PAVM by magnetic resonance angiography obviating the need for pulmonary angiography. ${ }^{42}$ The main reasons limiting the use of magnetic resonance angiography for

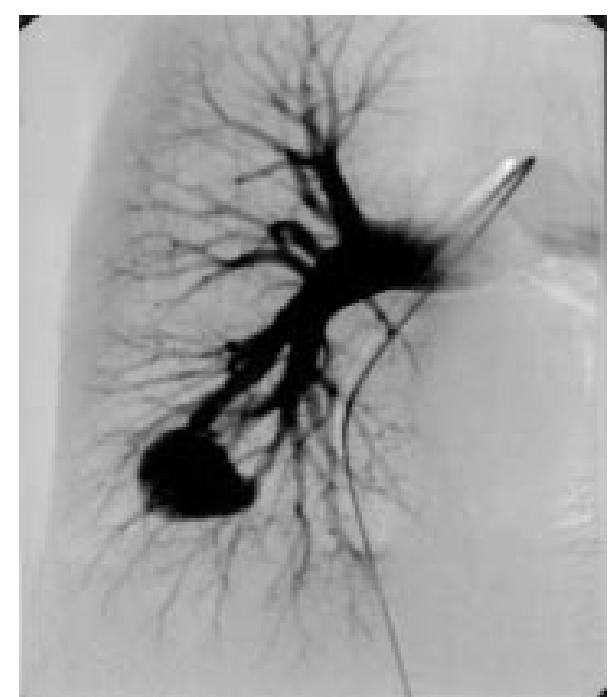

Figure 4 Angiogram showing large, single PAVM of right lower lobe with a single artery.

routine use are limited availability, relative expense, and the need for highly specialised staff to interpret the data.

In spite of all the advances in the techniques mentioned thus far, pulmonary angiography remains the gold standard in the diagnosis of PAVM (fig 4). ${ }^{12}{ }^{14}{ }^{16}$ Pulmonary angiography is justified to confirm the diagnosis in virtually all cases. A pulmonary angiogram not only identifies the PAVM but also further defines the angioarchitecture of pulmonary vasculature, which is necessary before therapeutic embolisation or surgical resection. Angiography should be performed on all portions of the lung to look for any unsuspected PAVM and source of intrathoracic or extrathoracic vascular communications. Computed tomography and magnetic resonance angiography, for the diagnosis of PAVM, should be reserved for those patients who cannot undergo angiography or for the follow up of patients with a proved PAVM.

In some patients with a normal chest radiograph, the presence of hypoxaemia signifies the existence of a small PAVM causing shunt. Contrast enhanced computed tomography may show multiple small PAVMs, which sometimes are not visible on pulmonary angiography because of their angiographically small size. The clinical significance of these small PAVMs is not clear at present.

At our institution, contrast enhanced computed tomography is done once a chest radiograph abnormality suspicious of PAVM is found. Contrast echocardiography is done to determine the presence of right-to-left shunt and shunt fraction is determined by the $100 \%$ oxygen method. Finally, if the patient is eligible for further intervention, pulmonary angiography is done to define anatomical details of the lesion.

\section{TREATMENT}

Although the first successful surgical resection of a PAVM was reported in $1942,{ }^{7}$ a consensus opinion of PAVM management has not been reached; one reason is the uncertainty of the natural history of PAVM. There is not a single prospective study of patients who were randomised to treatment versus observation only. There is evidence that PAVMs progressively enlarge over a period of time and incidence of progression is higher in patients with untreated PAVM. ${ }^{13}{ }^{15} 32$ The morbidity associated with PAVM was up to $50 \%$ in untreated patients compared with $3 \%$ in patients who received treatment. ${ }^{13} 1532$ There has been considerable overlap of cases in earlier studies, which makes it difficult to estimate the mortality. ${ }^{13-17}$ The mortality figure ranges from $0 \%$ to $55 \%$ in these 


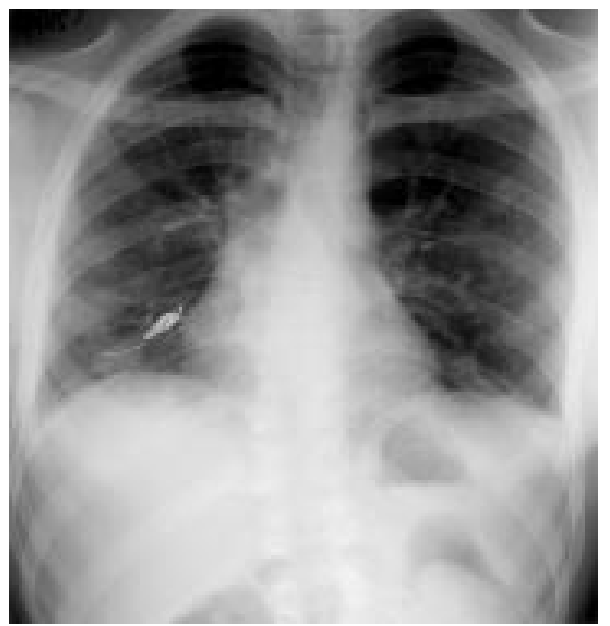

Figure 5 Chest radiograph showing complete occlusion of PAVM after coil embolisation.

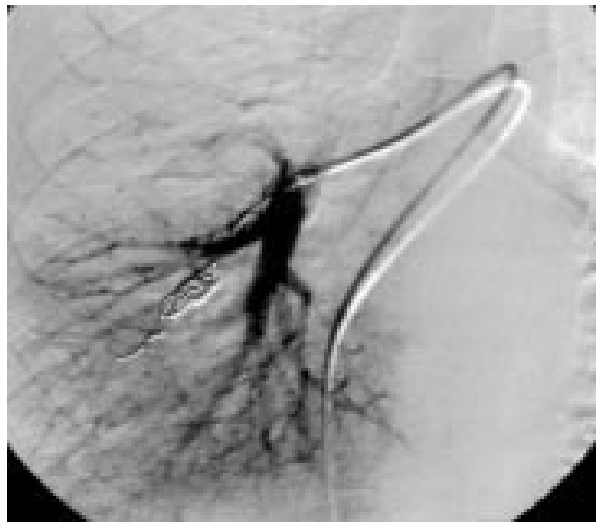

Figure 6 Angiogram showing nest of coils producing complete occlusion of PAVM.

studies. ${ }^{13} 1532$ In spite of limited information about the natural history of PAVM, available data suggest treatment should be offered to all symptomatic patients and asymptomatic patients with lesions less than $2 \mathrm{~cm}$ in diameter on chest radiography..$^{14}$ The purpose of treatment includes prevention of neurological complications, progressive hypoxia and its resultant effects, and high output cardiac failure.

Since the first successful resection of PAVM in 1942, surgery was the only treatment available until 1978, when Taylor et al reported the first successful percutaneous embolisation. ${ }^{71}$ The current preferred treatment for the majority of patients with a PAVM is percutaneous embolotherapy using coils or balloons; this method has largely replaced surgical intervention..$^{33}{ }^{34-45}$ Embolotherapy, being less invasive and easy to repeat, has definite advantages over surgery. Two methods have been used for embolisation-that is, balloons and metallic coils. Each method has its advantages, disadvantages, and complications. ${ }^{33} 3444$ Both techniques involve localisation of the PAVM by angiography followed by selective catheterisation of the feeding artery. ${ }^{33}{ }^{43}$ In coil embolisation, the catheter tip is positioned as close to the neck of PAVM as possible, a steel coil is advanced through the catheter and released at this point. ${ }^{43}$ Angiography is then repeated to ensure the position of the coil and to make certain the cessation of blood flow across the PAVM (figs 5 and 6). In balloon embolisation, after localisation of the PAVM by angiography, a balloon catheter is exchanged over guidewire and positioned at the neck of the feeding vessel..$^{33}$ The balloon is inflated and angiography is repeated to ensure vessel occlusion. If there is no flow across the PAVM, the balloon is detached.

Embolisation results are shown in table 1; a total of 808 PAVMs were occluded in 288 patients. Coil embolisation was used slightly more frequently than balloon embolisation. The overall success rate was over 99\% (808 attempts for 803 PAVM occluded). There was no reported mortality in these series. $^{33}{ }^{34} 4^{4-45}$ The most commonly encountered complication was self limiting pleuritic chest pain, which was seen in up to $13 \%$ of patients..$^{33} 46$ The incidence of pleuritic chest pain was higher $(31 \%)$ in patients with larger PAVMs (feeding vessel $>8$ $\mathrm{mm}) .{ }^{44}$ Pulmonary infarction was radiographically observed in $3 \%$ of patients. ${ }^{33}$ Air embolism during embolisation is rare, but can cause transient symptoms such as angina, bradycardia, and perioral paresthaesias. ${ }^{33}$ Other reported complications include device migration, myocardial rupture, cerebrovascular accident, vascular injury, early deflation of balloon, deep vein thrombosis, and pulmonary hypertension. ${ }^{33}{ }^{46} 47$ In summary, contemporary embolisation techniques with minimal morbidity and no mortality, renders radiological intervention as the first line of treatment for PAVM. Embolotherapy is a suitable alternative to surgical intervention in the elderly who are poor surgical candidates, in patients with multiple lesions, and patients who decline surgery. At our institution all patients with PAVM are evaluated by an interventional radiologist for embolotherapy before being considered for surgery.

Surgical resection of PAVMs is indicated in patients who fail embolotherapy, develop serious bleeding complication despite embolotherapy, have intrapleural rupture of the PAVM, or have untreatable contrast allergy and lesions not amenable to embolotherapy. Different surgical techniques have been employed which include local excision, segmental resection, lobectomy, ligation, and even pneumonectomy. Lung conserving resection, local resection, or segmentectomy is the procedure of choice whenever possible. Staged bilateral thoracotomies were performed in a case of an extensive bilateral PAVM. ${ }^{48}$ Recently video assisted thoracoscopy has been employed in the resection of a small PAVM ${ }^{49}$ PAVM surgery has the same risk as any other thoracic surgery procedure, but when properly performed in well selected patients, it results in minimal morbidity and mortality. ${ }^{10}{ }^{13}{ }^{15}$ The reported mortality in a case series published after 1960 is zero. ${ }^{13-15}{ }^{34}$ In summary,

Table 1 Outcome of patients undergoing embolisation for PAVM

\begin{tabular}{|c|c|c|c|c|c|c|c|}
\hline Author & $\begin{array}{l}\text { No of } \\
\text { patients }\end{array}$ & $\begin{array}{l}\text { Embolisation } \\
\text { type* }\end{array}$ & $\begin{array}{l}\text { No of PAVMs } \\
\text { attempted }\end{array}$ & $\begin{array}{l}\text { No of PAVMs } \\
\text { occluded }\end{array}$ & $\begin{array}{l}\text { Device } \\
\text { migration }\end{array}$ & $\begin{array}{l}\text { PAVM } \\
\text { recanalisation }\end{array}$ & $\begin{array}{l}\text { Follow up } \\
\text { periodt }\end{array}$ \\
\hline White et al, $1988^{33}$ & 76 & $B \gg C$ & 276 & 276 & 2 & NR & NR \\
\hline Haitjema et al, $1995^{34}$ & 32 & C & 92 & 90 & 2 & 2 & $\begin{array}{l}2-71 \text { months } \\
\text { (25 months) }\end{array}$ \\
\hline Dutton et al , $1995^{50}$ & 53 & C & 102 & 102 & 2 & NR & NR \\
\hline Lee et al, $1997^{51}$ & 45 & $B=C$ & 98 & 97 & 2 & 4 & $\begin{array}{l}1-12.3 \text { years } \\
\text { (4.7 years) }\end{array}$ \\
\hline Saluja et al, $1999^{52}$ & 82 & $B>C$ & 240 & 238 & 1 & 3 & $1-4$ years \\
\hline
\end{tabular}

NR, not reported

${ }^{*} \mathrm{~B}$, balloon; $\mathrm{C}$, coil. †Mean in parentheses. 
Table 2 Mortality and morbidity in untreated PAVMs

\begin{tabular}{|c|c|c|c|c|}
\hline Author & $\begin{array}{l}\text { Untreated } \\
\text { cases }\end{array}$ & $\begin{array}{l}\text { PAVM related } \\
\text { morbidity (\%) }\end{array}$ & $\begin{array}{l}\text { PAVM related } \\
\text { mortality (\%) }\end{array}$ & $\begin{array}{l}\text { Follow up period } \\
\text { (years) }\end{array}$ \\
\hline Yater et al, $1949^{53 *}$ & 17 & NR & 29 & NR \\
\hline Muri, $1955^{54 *}$ & 48 & NR & 25 & NR \\
\hline Stringer et al, $1955^{1 *}$ & 41 & 31 & 17 & NR \\
\hline Sluiter-Eringa et al, $1969^{15} \dagger$ & 13 & 15 & 8 & 7 \\
\hline Dines et al, $1974^{13} \dagger$ & 27 & 26 & 11 & 6 \\
\hline Puskas et al, $1993^{32} \dagger$ & 4 & 50 & 0 & 10 \\
\hline
\end{tabular}

NR, not reported.

* Literature review; $\uparrow$ studies of consecutive patients from single institution.

surgical resection of a PAVM is an acceptable option in those patients who are not amenable to embolotherapy. It is associated with minimal mortality and morbidity and requires a hospital stay.

Mortality and morbidity in untreated PAVMs is shown in table 2 .

\section{CONCLUSION}

PAVMs are an uncommon clinical problem. The classic triad of dyspnoea on exertion, cyanosis, and clubbing should alert the clinician to the possibility of a PAVM. There is a strong association between PAVM and HHT. All patients with PAVMs should be screened for cerebral arteriovenous malformation by contrast enhanced head computed tomography or magnetic resonance imaging. The chest radiograph often suggests the diagnosis of PAVM and contrast enhanced computed tomography or pulmonary angiography is usually diagnostic. Contrast echocardiography confirms the presence of right-toleft shunt and shunt fraction can be measured by the $100 \%$ oxygen method or by radionuclide perfusion lung scanning. Pulmonary angiography is necessary before embolotherapy or surgical intervention, to document number and location of all lesions. A simplified approach to diagnose and/or to follow up a PAVM is presented in fig 7. Embolotherapy, where available,

- Patient suspected of having PAVM

- Patient with clinical features of HHT

- Follow up in a patient treated for PAVM

- Follow up in a patient with HHT

Chest radiograph and

arterial blood gas $(A B G)$ on room air

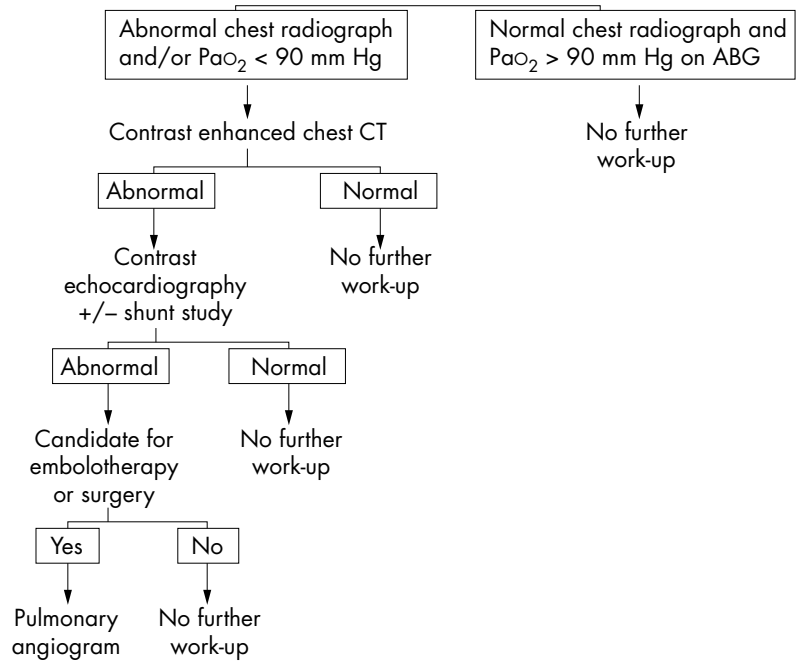

Figure 7 An approach in patients suspected of having a PAVM or to follow up patients with PAVM. is a relatively safe and effective procedure and the preferred treatment for PAVMs. Lung conserving resection is the optimal option for symptomatic patients where embolotherapy was unsuccessful or technically not feasible. The risk of serial growth of occult lesions and recanalisation of previously embolised PAVM dictates that patients should have a regular follow up.

\section{Authors' affiliations}

I Khurshid, G H Downie, Department of Pulmonary and Critical Care Medicine, Brody School of Medicine, East Carolina University, Greenville, North Carolina, USA

\section{REFERENCES}

1 Stringer CJ, Stanley AL, Bates RC, et al. Pulmonary arteriovenous fistulas. Am J Surg 1955:89:1054-80.

2 Le Roux BT. Pulmonary hamartomas. Thorax 1964;19:236-43.

3 Churton T. Multiple aneurysms of pulmonary artery. BMU 1897;i: 1223.

4 Wilkins GD. Ein Fall von multiplen pulmonalis anerysmen. Beitr Klinis Tuberk 1917;38:1-10

5 Rhodes CB. Cavernous hemangiomas of lung with secondary polycythemia. JAMA 1938;110:1914-5.

6 Smith HL, Horton BT. Arteriovenous fistula of the lung associated with polycythemia vera; report of case in which the diagnosis was made clinically. Am Heart J 1939; 18:589-92.

7 Hepburn J, Dauphinee JA. Successful removal of hemangioma of lung followed by disapperance of polycythemia. Am J Med Sci 1942:204:681-7.

8 Packard GB, Waring JJ. Arterio-venous fistula of the lung treated by ligation of the pulmonary artery. Arch Surg 1945;56:724-40.

9 Lindskog EE, Liebow AA, Lausel $\mathrm{H}$, et al. Pulmonary arteriovenous aneurysm. Ann Surg 1950;132:591-600.

10 Bosher LH, Blake DA, Byrd BR. An analysis of the pathologic anatomy of pulmonary arteriovenous aneurysms with particular reference to the applicability of local excision. Surgery 1959;45:91-104.

11 Taylor BG, Codkerill EM, Manfredi F, et al. Therapeutic embolization of the pulmonary artery in pulmonary arteriovenous fistula. Am J Med 1978:64:360-5

12 Prager RL, Law KH, Bender HW Jr. Arteriovenous fistula of the lung. Ann Thorac Surg 1983;26:231-9.

13 Dines DE, Arms RA, Bernatz PE, et al. Pulmonary arteriovenous fistulas. Mayo Clin Proc 1974:49:460-5.

14 Dines DE, Deward JB, Bernatz PE. Pulmonary arteriovenous fistula. Mayo Clin Proc 1983;58:176-81.

15 Sluiter-Eringa H, Orie NGM, Slutier HJ. Pulmonary arteriovenous fistula: diagnosis and prognosis in non-complaint patients. Am Rev Respir Dis 1969:100:177-84.

16 Monsour KA, Hatcher CR Jr, Logan WD, et al. Pulmonary arteriovenous fistula. Am Surg 1970;37:203-8

17 Hodgson $\mathrm{CH}$, Kaye RL. Pulmonary arteriovenous fistula and hereditary telangiectasia. Dis Chest 1963;43:449-55.

18 Marchuk DA. The molecular genetic of hereditary hemorrhagic telangiectasia. Chest 1997;111:79-82S.

19 Porteous MEM, Curtis A, Williams O, et al. Genetic heterogeneity in hereditary haemorrhagic telangiectasia. J Med Genet 1994;31:925-6.

20 Symbas PN, Goldman M, Erbesfeld MH, et al. Pulmonary arteriovenous fistula, pulmonary artery aneurysm, and other vascular changes of the lung from penetrating trauma. Ann Surg 1980;191:336-40.

21 Moore JW, Kirby WC, Madden WA, et al. Development of pulmonary arteriovenous malformations after modified Fontan operation. J Thorac Cardiovasc Surg 1989;98:1045-50.

22 Pierce JA, Reagan WP, Kimball RW. Unusual cases of pulmonary arteriovenous fistulas, with a note on thyroid carcinoma as a cause. $N$ Engl J Med 1959;260:901-7.

23 LeRoux T, Gibb BH, Wainwright J. Pulmonary arteriovenous fistula with bilharzial pulmonary hypertension. Br Heart J 1970;32:571-4.

24 Kamei K, Kusumoto K, Suzuki T. Pulmonary amyloidosis with pulmonary arteriovenous fistula. Chest 1989;96:1435-6. 
25 Esplin MS Varner MW. Progression of pulmonary arteriovenous malformation during pregnancy. Obstet Gynecol Surv 1997;52:248-53. 26 Hoffman R, Robins R. Evolving pulmonary nodule: multiple pulmonary arteriovenous fistulas. AJR Am J Roentgenol 1974;120:861-4.

27 Ference BA, Shannon TM, White RI Jr, et al. Life-threatening pulmonary hemorrhage with pulmonary arteriovenous malformations and hereditary hemorrhagic telangiectasia. Chest 1994;106:1387-90.

28 Moore BP. Pulmonary arteriovenous fistulas. Thorax 1969;24:381.

29 Schumaker HB, Waldhausen JA. Pulmonary arteriovenous fistulas in children. Ann Surg 1963;158:713-20.

30 Anabtawi IN, Ellison RG, Ellison LT. Pulmonary arteriovenous aneurysms and fistulas. Ann Thorac Surg 1965;1:277-85.

31 Cooley DA, McNamara DG. Pulmonary telangiectasia: report of a case proved by pulmonary biopsy. J Thorac Surg 1954;27:614-22.

32 Puskas JD, Allen MS, Moncure AC, et al. Pulmonary arteriovenous malformations: therapeutic options. Ann Thorac Surg 1993;56:253-8.

33 White RI Jr, Lynch-Nyhan A, Terry P, et al. Pulmonary arteriovenous malformations: techniques and long-term outcome of embolotherapy. Radiology 1988;169:663-9

34 Haitiema TJ, Overtoom TTC, Westermann CJJ, et al. Embolization of pulmonary arteriovenous malformations: results and follow up in 32 patients. Thorax 1995;50:719-23

35 Barzilai B. Waggoner AD, Spesset C, et al. Two-dimensional contras echocardiography in the defection and follow up of congenital pulmonary arteriovenous malformations. Am J Cardiol 1991;68:1507-10.

36 Whyte MKB, Peters AM, Hughes JMB, et al. Quantification of right-to-left shunt at rest and during exercise in patients with pulmonary arteriovenous malformations. Thorax 1992;47:790-6.

37 Remy J, Remy-Jardin M, Wattinne L, et al. Pulmonary arteriovenous malformation: evaluation with $\mathrm{CT}$ of the chest before and after treatment. Radiology 1992;182:809-16

38 Remy J, Remy-Jardin M, Giravd F, et al. Angioarchitecture of pulmonary arteriovenous malformations: clinical utilities of three-dimensional helical CT. Radiology 1996:191:657-64.

39 Halbsguth A, Schlze W, Ungeheuer E, et al. Pitfall in the CT diagnosis of pulmonary arteriovenous malformations. J Comput Assist Tomogr 1983;7:710-2

40 Silverman JM, Jubien PJ, Herkens RJ, et al. Magnetic resonance imaging evaluation of pulmonary arteriovenous malformation. Chest 1994:106:1333-8.
41 Rotondo AM, Scialpi M, Scialpic C. PAVM: evaluation by MR angiography. AJR Am J Roentgenol 1997;168:847-9.

42 Brown JJ, Gilbert T, Gamsu G, et al. MR imaging of low signal intensity pulmonary lesions: using flow-sensitive techniques. J Comput Assist Tomogr 1988;12:560-64.

43 Dutton JAE, Jackson JE, Huges JMB, et al. Pulmonary arteriovenous malformations: results of treatment with coil embolization in 53 patients. AJR Am J Roentgenol 1995; 165:1119-25.

44 Saluja S, Sitko L, Lee RW, et al. Embolotherapy of pulmonary AVM with detachable balloons: long-term durability and efficiency. J Vasc Interv Radiol 1999; 10:883-9

45 Lee RW, White RI, Egglin TK, et al. Embolotherapy of large pulmonary arteriovenous malformations: long-term results. Ann Thorac Surg 1997;64:930-40

46 Remy-Jardin RM, Wattinne L, Remy J. Transcatheter occlusion of pulmonary arterial circultaion and collateral supply: failure, incidents and complications. Radiology 1991;180:699-705.

47 Haitjema T, ten Berg JM, Overtoon TTC, et al. Unusual complications after embolization of a pulmonary arteriovenous fistula. Chest 1996;109:1601-6.

48 Brown SE, Wright PW, Renner JW, et al. Staged bilateral thoracotomies for multiple pulmonary arteriovenous malformations complicating hereditary hemorrhagic telangiectasia. J Thorac Cardiovasc Surg 1982;83:285-9.

49 Minami M, Fujii Y, Mizuta T, et al. Video-assisted thoracoscopic excision of pulmonary arteriovenous fistula. J Thorac Cardiovasc Surg 1996:112:1395-7.

50 Dutton JAE, Jackson JE, Hughes JMB, et al. Pulmonary arteriovenous malformations: Results of treatment with coil embolization in 53 patients. AJR Am J Roentgenol 1995; 165:1119-25.

51 Lee DW, White RI, Egglin TK, et al. Embolotherapy of large pulmonary arteriovenous malformations: long term results. Ann Thorac Surg 1997;64:930-9.

52 Saluja S, Sitko I, Lee DW, et al. Embolotherapy of pulmonary arteriovenous malformations with detachable balloon: long term durability and efficacy. J Vasc Interv Radiol 1999;10:883-9.

53 Yater WM, Finnegan J, Griffin HM. Pulmonary arteriovenous fistula (varix). JAMA 1949;141:581-9.

54 Muri JW. Arteriovenous aneurysms of the lungs. Am J Surg 1955:89:265-71. 